\title{
Inflation and Price Setting in a Natural Experiment
}

\author{
Jerzy D. Konieczny \\ Department of Economics \\ Wilfrid Laurier University \\ Waterloo, Ont., Canada, N2L 3C5 \\ jkoniecz@wlu.ca
}

\author{
Andrzej Skrzypacz \\ Department of Economics \\ Harkness Hall \\ University of Rochester \\ Rochester, NY 14627, USA \\ skrz@troi.cc.rochester.edu
}

November 9, 1999

\begin{abstract}
We analyze the behaviour of prices using a large disaggregated data set for Poland during transition from a planned to a market economy. The size of price changes and the frequency of adjustment both fall as the inflation rate declines. Price setters follow a mixture of state- and time-contingent policies. We find that price setters are forward-looking. Intermarket price variability increases with inflation and the effect of expected inflation is much stronger than the effect of unexpected inflation. So the bottom line is this: it takes sellers of sausage, eggs, toothpaste, vacuum cleaners, car-wash operators etc. just a few years to figure out how to adjust prices in a market environment. Our results support both the menu cost, and the rational expectations, hypotheses.
\end{abstract}

We would like to thank Gerard Llobet, Paul Storer and seminar participants at the National Bank of Poland and at Warsaw University, as well as participants of CEA meetings in Ottawa and LACEA meetings in Buenos Aires for helpful comments and suggestions. We are responsible for any errors. The first author acknowledges financial support from Social Sciences and Humanities Research Council of Canada, grant \# 410-96-0245. 


\section{Introduction.}

We study the behaviour of price setters using a large disaggregated data set for Poland. There are several reasons why the Polish data are interesting. The period under analysis covers the transition from a centrally planned to a market economy. Until 1990 most prices in Poland were controlled. The big-bang reform (see Sachs, 1993 for details) involved the freeing of almost all prices at once. Dramatic changes in the economy created a natural experiment; the large data set we use allow to study in detail the behaviour of price setters in the new environment. The natural experiment setting raises several interesting questions, relevant both to the issues of transition as well as to the more general issues related to expectation formation. How do firms set prices following a regime shift, in an unstable environment without history on which to base expectations? Would their pricing policies be similar or different to those observed elsewhere? How fast do people learn? Is it possible to pin down their expectations?

There are two basic theories which explain the relationship between the rate of inflation and relative price variability. The menu cost approach (Sheshinski and Weiss, 1977) implies that variability depends on expected inflation. The aggregate/individual confusion approach (Lucas, 1973) postulates that it is the unexpected component of inflation that matters. ${ }^{1}$

Our results are summarized as follows:

- duration of price quotations is inversely, while the size of price changes is positively, correlated with the inflation rate;

- $\quad$ relative price variability is positively related to inflation;

1 In contrast, Ball and Mankiw (1995) argue that inflation is caused by relative price variability. Their argument is relevant only to low-inflation environments. 
- $\quad$ expected inflation has a bigger effect on relative price variability than unexpected inflation;

- $\quad$ firms follow a mixture of state- and time-contingent pricing policies;

- $\quad$ price behaviour is forward-looking;

- $\quad$ relative price variability falls over time, but at a decreasing rate;

- $\quad$ the most variable are prices of services and durable goods; the least variable are prices of perishable foodstuffs.

The first three results are the same as in Lach and Tsiddon (1992) who analyze a similar disaggregated data set for Israel. Their data cover the period of 1978-1984, which follows a decade of very rapid inflation. As is well known, the long inflationary period led to many changes in the Israeli economy which aimed to reduce its negative effects. In particular, it can be expected that a typical Israeli firm developed optimal, or near optimal, pricing policies to deal with high aggregate inflation rate. We treat Lach and Tsiddon's (1992) results as a benchmark and so the bottom line is this: even in an entirely new economic environment, sellers of sausage, eggs, toothpaste, vacuum cleaners, car-wash operators etc. require just a few years to figure out how to form inflationary expectations and adjust prices in a market environment. Together with the evidence that price setters are forward looking, this provides strong support for the rational expectations hypothesis. In addition, as in Lach and Tsiddon (1992), data appear to support the menu cost explanation of relative price variability over the aggregate/individual confusion of the Lucas' type.

The plan of the paper is as follows. The data are described in section 2. This is followed by nonparametric analysis. In section 4 we ask whether pricing policies are time- or state-contingent. The relationship between inflation and price variability is analyzed in section 5. In section 6 we provide evidence that agents are forward looking. The last section 
concludes.

\section{Data.}

The data set consists of price information on individual products and services in Poland. The prices are the actual transaction prices, as coupons or discounts were very rare to nonexistent over the study period. The data were collected by the Polish Central Statistical Office (GUS) in order to calculate the Consumer Price Index. GUS collects price information on 1500-1800 products in 307 districts, with one store per district (Bauc et al, 1996, p. 55). Out of this set we have a balanced sample of data for 52 goods in 47 stores (districts) each. The data comprise the complete set for four out of 49 administrative districts in Poland (Voivodships). We also have Voivodship (49) and national averages for all goods; this data provide information on own price inflation.

In order to be included in our data, each product has to meet several criteria. Most importantly, we require that it did not change during the period in question. We exclude goods and services with regulated prices, and several products with many missing observations. Finally, we want to have data on a variety of products. This is difficult as a lot of goods have changed following the collapse of the planned economy. In the end, out of the 52 products, 37 are groceries (19 perishable and 18 storable), 2 are sold in cafeterias/cafes, 10 are nongrocery items and 3 are services. The list of the products is in Appendix A.

The frequency of observations varies over time and across goods. There are 2-4 observations per month for 1990 and 1-3 observations a month for the period 1991-96, depending on the good. As we would like to take advantage of the variety of products in the data, for a part of our study we use the first observation in each month. For foodstuffs there are 4 observations a month in 1990 (except in December 1990, when prices were not 
collected in the last week) and 3 observations a month for the period 1991-96. Hence for a subsample of goods (the 37 foodstuffs listed in appendix A plus one perishable and two durable foodstuffs) we also use the more frequent (three observations a month) data for the period 1991-96.

One problem with the data is that we do not know the identity of the store where a price is being sampled. The sampling procedure is as follows. Each Voivodship is divided into several districts (for example, there are 14 districts in Warsaw) ${ }^{2}$. One store is chosen in each district. The instructions for price inspectors are to choose the same store each time, but this is not enforced and changes of stores are not recorded.

Apart from this technical issue, some changes are due to the transformation in the retail sector following the collapse of the planned system. Table 1 below provides data on the changes in store ownership in the country as a whole. It understates ownership changes, since many private stores were small (100-200 sq. feet) and were less likely to be visited by price inspectors than state or cooperative stores. Also, a store may change its pricing strategy due to, for example, management change. Finally, while we took great care to select goods which did not change during the period in question, the competitive environment was altered both by increased availability of substitutes as well as changes in the retail and service sectors. ${ }^{3}$

\section{Preliminary Analysis.}

We begin the analysis by taking a cursory look at the data. They are illustrated in

${ }^{2}$ We picked the Voivodships with the largest number of districts.

${ }^{3}$ For example, the price for carwash service (good number 49 ) is the price for washing a specific make and type, but during the period 1990-96 the car became much less common and there appeared carwashes offering different levels of service. 
Figure 1 We plot the proportion of missing observations, the inflation rate, and the proportions of increased, unchanged and decreased prices as well as the ratio of decreases to increases. The quality of the data (as measured by the proportion of nonmissing observations) improves systematically over time. This is not due to market shortages as these disappeared quickly within the first few months following the big-bang transition, while the proportion of missing data falls throughout the sample period ( in 1991 (1994) it is 74\% (43\%) of its value in 1990; the percentage drop in the proportion between 1993 and 1994 is similar to that between 1990 and 1991).

The inflation rate is the 12-month price increase December to December ${ }^{4}$. The rate in 1990 was $249 \%$ (due to the price shock following the freeing of most prices in January 1990) and is omitted from the graph for clarity. The inflation rate has been falling systematically over time. Over 12 month periods the yearly inflation rate has increased, compared to the analogous period in the previous year, only in March 1993, Oct-Nov 1994 and Feb-May 1995. Note, however, that monthly inflation is much more erratic and increases in monthly inflation are frequent.

All series follow a similar, nearly monotonic, pattern: the proportion of price increases and of price decreases falls while the proportion of prices which are left unchanged rises; also, price decreases become relatively less common over time than price increases, except for 1991.

Information on the duration of prices and on the size of price changes is in Table 2. The average duration of prices rises over time as the inflation rate falls, with the exception of 1995. The same pattern is observed at the level of individual goods, but with several

${ }^{4}$ As the inflation rate rapidly declined over the sample period, the choice of the month affects the size of the inflation rate but the general picture remains unchanged. 
exceptions. ${ }^{5}$ The average duration over the sample period varies between 1.33 months for eggs and 5.75 months for ECG test ${ }^{6}$. Generally speaking, duration is shortest for perishable foodstuffs and longest for manufactured products.

The average size of price increases falls as the inflation rate declines over time, again with the exception of 1995 . It varies from over $30 \%$ in 1990 to about $10 \%$ in 1994-96, after the inflation rate has fallen from the high levels which followed the initial price shock. For individual goods the average size of changes varies from $7.1 \%$ for one of the meat products to $36 \%$ for ECG test. Price changes are the smallest for perishable foodstuffs (in particular meats) and the largest for manufactured products.

The average size of price decreases falls in the first four years and increases somewhat in the last three. The changes in the size of price decreases are much smaller than in the case of price increases. While in 1990 the average decrease is equal to about $40 \%$ of average increase, in the last three years they are of similar size. Decreases are smallest for foodstuffs and largest for services and manufactured products.

As sampled stores may change over time, some of price changes may be an artifact of the sampling procedure. ${ }^{7} \quad$ The recorded proportion of price decreases varies between $27 \%$ in 1990 and $15 \%$ in 1996 of all price changes. These numbers appear to be large, judging by earlier results. Cross-country evidence suggests that price decreases become more frequent as the rate of inflation rises. This empirical relationship is apparent by comparing low-inflation economies with economies with high rates of inflation. In Cecchetti (1986) and in Konieczny

5 Duration falls, in comparison with the preceding year, in 5 cases in 1991, 7 in 1992, 8 in 1993, 19 in 1994, 38 in 1995 and 12 in 1996, out of possible 52.

${ }^{6}$ The extreme values are 1.07 for eggs in 1990 and 11.72 for ECG test in 1994.

${ }^{7}$ This problem is evident in Parsley (1996). 
and Fisher (1999a) the inflation rate is $0.2-12 \%$ per year and there are no price decreases; in Sheshinski, Tishler and Weiss (1979) inflation is $0.25-2.9 \%$ per month and $2 \%$ of changes are decreases; in Lach and Tsiddon (1992) inflation is over $4 \%$ per month and $15 \%$ of changes are decreases; in Tommasi (1993) the inflation rate is $-5 \%$ to $38 \%$ per week and there are $36 \%$ price decreases. One exception is Dahlby (1992); in his data inflation is $8-12 \%$ and there are $7 \%$ price cuts. The intuition is that, as the rate of inflation is high, the behaviour of prices is more erratic and mistakes or price experimentation on the part of the price setters happen more often. ${ }^{8}$ Additional reasons for recorded price changes are a temporary unavailability of goods, changes in ownership and changes in pricing strategies. It is not likely that these factors dominate the pricing behaviour. If price changes were due to changes in sampled stores (or in pricing policies) their distributions would be generated by random sampling from the contemporaneous distribution of price levels. In Konieczny and Skrzypacz (1999), however, we find that the distribution of price levels rapidly changes to long-run values. The probability of finding a price which is over $10 \%(20 \%, 30 \%)$ away from the geometric mean of prices of the given good is $52 \%$ (28\%, $16 \%$, respectively) in January 1990 , falls to $30 \%$ (14\%, 6\%, respectively) by January 1991 and varies little throughout the rest of the sample. In contrast, the average size of price increases falls continuously until 1995, and the average size of price increases falls continuously until 1994. Finally, as we show below, price changes are related to various measures of inflation; this relationship is unlikely to be generated by store changes.

${ }^{8}$ In a companion paper (Konieczny and Skrzypacz, 1999) we find, in the early stage of transition, evidence of learning how to set price in the new environment. Moreover, we find that the more intensive is search for the best price, the more likely is the store to learn actively by changing its price often. This tinkering with prices may be responsible for the large proportion of decreases in the early years. 
To sum up, as inflation falls price changes become less frequent. This is consistent with earlier findings (Sheshinski, Tishler and Weiss, 1981, Cecchetti, 1986, Danziger, 1987, Dahlby, 1991, Lach and Tsiddon, 1992, Tommasi, 1993, Kashyap, 1995 and Fisher and Konieczny, 1999a). The finding that the size of price changes falls as inflation declines is less common: in Sheshinski, Tishler and Weiss (1981) and in Cecchetti (1986) there is little effect of inflation on adjustment size, while Lach and Tsiddon (1992) and Kashyap (1995) find several instances when price change become larger as inflation falls. ${ }^{9}$

\section{Do Price Setters Follow Time- or State-Contingent Pricing Policies?}

The nature of price setting policies is of crucial importance in macroeconomics. If price setters change prices on a time-contingent basis (for example once a quarter), monetary shocks have large effects on output as prices are fixed in the short run. These effects are persistent when individual decisions are staggered (Fischer, 1977 and Taylor, 1980). On the other hand, if pricing policies are state-contingent, monetary policy is less effective (Caplin and Spulber, 1987, provide an example of an economy in which state-contingent policies result in a situation in which most individual nominal prices are fixed but monetary policy is ineffective; see, however, Caplin and Leahy, 1992).

The behaviour of prices summarized in the previous section indicates that price setters follow policies that are, at least to some extent, state contingent. The high-frequency data (3 observations a month) for 40 foodstuffs listed in Appendix A, allow us to take a closer look at

9 It is worth noting that the standard menu-cost model (Sheshinski and Weiss, 1977) implies that, as the rate of inflation rises, the size of price changes increases while the effect on the frequency of price changes is ambiguous. A sufficient condition for the frequency to increase is that the profit function of the price setter be quasiconcave in the log of real price. A detailed review of empirical results is in Fisher and Konieczny (1999a). 
the clustering of price changes over time. Table 4 summarizes the information on the proportion of price changes by each 10-day period. Price changes are concentrated in the first 10 days of each month: with the exception of price increases in 1991 more than half of all changes take place in the first 10 days of each month. ${ }^{10}$

What determines the time-contingent behaviour of changing prices at the beginning of the month? Tables 2 and 4 indicate that the tendency to cluster price changes is inversely related to the frequency of price changes. At the beginning of the period, when prices were changed often, the proportion of changes in the first 10 days of each month is relatively low. The proportion increases as price changes become less frequent. This is supported by crosssectional evidence. The across-goods correlation coefficient between, on one hand, the proportion of price increases (among nonmissing observations) each month and, on the other hand, the proportion of all increases which take place in the first 10 days of each month is 0.79 ; the corresponding number for decreases is -0.64 .

There is little tendency for price changes to cluster in particular months. The proportion of price changes varies between $15.8 \%$ in September and $10.2 \%$ in June. Excluding June, August and September the proportion varies between $12.9 \%$ in January and $11.3 \%$ in February. The large value in August and September is due to the fact that meats, which constitute almost a quarter of the sample, all have the highest proportion of changes in that month (excluding meats, the proportion varies between $13.1 \%$ in September and $10.4 \%$ in November). Finally, there is little clustering across months in quarters. The proportion of price changes varies between $12.6 \%$ in the third month of each quarter and $12.2 \%$ in the first and the second month of each quarter. Price increases, as well as price decreases, also show

10 It is possible changes take place at the beginning of each month (first working day), but we have no data to support, or disprove, this hypothesis. 
little tendency to cluster in particular months or quarters.

These findings imply that firms follow a mixture of state- and time-contingent pricing policies. They prefer to change prices at the beginning of each month but this tendency manifests itself only when price changes are relatively rare, and so the change in timing required to adjust at the beginning of the month, rather than at the optimally chosen time, is relatively insignificant. When price changes are frequent, the change in timing from optimal to the beginning-of-the- month strategy matters and stores are more likely to change prices during the month.

\section{Inflation and Relative Price Variability.}

We now turn to the analysis of the relationship between inflation and relative price variability.

\section{V.1. Theory and Empirical Evidence.}

In a frictionless classical world, inflation (expected or not) should have no effect on relative price variability. Variability should be affected by real variables only: changing market conditions (for example, competitiveness), production technology, demand and so on. In a classical world money is neutral. Hence the relationship between inflation and price variability is an aspect of monetary nonneutrality, or of monetary nonsuperneutrality.

There are two main approaches which address the relationship between inflation and relative price variability. In the first, monetary nonneutrality is the result of nominal rigidities. The most important of those for our study is the menu cost approach, where price setters face costs of changing prices. In addition, there are many models in which nominal variables are not perfectly flexible and so inflation affects relative price variability through 
different response elasticities, effects on coordination of price changes and so on. A review of those theories is beyond the scope of this paper; we concentrate on the menu cost approach. In the aggregate/local confusion approach, money is not neutral due to limited information available to price setters. They are discussed in turn.

The menu cost approach, started by Barro (1972) and developed by Sheshinski and Weiss (1977, 1983) and others, is based on the assumption that changing nominal prices is costly. The costs may be the literal costs of adjusting price (deciding on the new price, informing salespeople, customers, printing new prices etc) or the costs of unfavourable reaction of customers and/or competitors to frequent or large price changes. While the literal costs are considered trivial (but see Levy et al, 1997 for some evidence on the size of the costs), the second type of costs may be significant. In any case, the fact that individual nominal prices remain constant for extended periods of time suggests that the costs of adjustment are large (see Fisher and Konieczny, 1999a, for a review of menu cost models and empirical evidence).

Lach and Tsiddon (1992) discuss the relationship between inflation and relative price variability implied by the menu cost model. Their argument is based on the implicit assumption that, whenever the rate of inflation changes, price bounds are revised. Increases in the inflation rate lead to a larger amplitude of price changes (Sheshinski and Weiss, 1977 and 1983).

If price changes are not synchronized, this implies a higher variability of relative prices; this effect is amplified by store heterogeneity. Note, however, that while the price changes do appear to be staggered (see Lach and Tsiddon, 1992 and 1996, Tommasi, 1993, and Fisher and Konieczny, 1999b) empirical studies find many instances when the size of price changes falls as inflation increases. 
The aggregate/local confusion approach (Lucas, 1973) suggests that the reason for nominal rigidity is the inability of agents to distinguish between local and aggregate shocks. Combined with differences in supply and demand elasticities, in the history of local shocks and in their persistence (Barro, 1976, Cukierman, 1984), this generates a positive effect of unexpected inflation on relative price variability. In contrast to the menu cost model, expected inflation does not lead to confusion and so has no effect on variability. ${ }^{11}$

The relationship between inflation and relative price variability has been analyzed by Mills (1927), Vinning and Elwertowski (1976), Parks (1978), Fisher (1981), Domberger (1987), Van Hoomissen (1988), Lach and Tsiddon (1992), Parsley (1996) and Debelle and Lamont (1997), among others. The general conclusion of this literature is that various measures of relative price variability are positively related to inflation.

Lach and Tsiddon (1992) extend empirical literature by analyzing the effect of expected and unexpected inflation on relative price variability. Their evidence is based on a disaggregated data set on prices of foodstuffs in Israel during 1978-1984. They find that it is the expected inflation, rather than the unexpected one, which is responsible for the positive relationship between inflation and relative price variability.

\section{V.2. Measures of Price Variability.}

Parks (1978) proposed that variability be measured by the cross-sectional variance of rates of change of prices. This measure has been used by, for example, Domberger (1987), Van Hoomissen (1988) and Lach and Tsiddon (1992). Define the price of good $i$ in store $j$ at

${ }^{11}$ Ball and Mankiw (1995) have recently suggested that the causation runs from price variability to inflation. Their argument is based on a symmetric distribution of desired prices and reluctance to reduce nominal values. As the variance of desired prices increases, the average value of those desired prices which involve a higher price rises. As a result the inflation rate increases. Prices in Poland appear to be flexible downwards and so their argument is not applicable to the Polish situation. 
time $t$ as $P_{i j t}$. Whenever we have two consecutive observations in a given store we can calculate its rate of change between $t-1$ and $t: D P_{i j t} \equiv \ln P_{i j t}-\ln P_{i j t-1}$. Relative price variability is measured by the standard deviation of $D P_{i j t}$ across stores:

$$
S D P_{i t} \equiv\left[\frac{1}{N_{i t}-1} \sum_{j}\left(D P_{i j t}-D P_{i t}\right)^{2}\right]^{1 / 2}
$$

where $N_{i t}$ is the number of observations in which price change could be observed (ie the number of two consecutive nonmissing observations) and $D P_{i t} \equiv\left(1 / N_{i t}\right) \Sigma_{j} D P_{i j t}$ is the insample rate of inflation of good $i$ at time $t$.

We also test the relationship with the coefficient of variation of price levels across stores, $C V_{i j}$ :

$$
C V_{i t} \equiv\left[\frac{1}{N_{i t}-1} \sum_{j}\left(\frac{P_{i j t}-P_{i t}}{P_{i t}}\right)^{2}\right]^{1 / 2}
$$

where $P_{i t} \equiv\left(1 / N_{i t}\right) \Sigma_{j} P_{i j t}$ is the average price of good $i$ across stores at time $t$.

The reason for using $C V$ as well is that the two measures have opposing implications for consumer search. ${ }^{12}$ High variability of the rates of change of prices implies rapid depreciation of price information; hence it discourages search. High variability of price levels across stores increases incentives to search.

\section{V.3. Measuring Expected Inflation.}

A priori, it is difficult to predict the nature of the relationship between inflation and relative price variability. The problem is as follows. Both the menu cost and the aggregate/local confusion approaches suggest that the relationship depends on the division of

12 In Konieczny and Skrzypacz (1999) we find that search for the best price has major impact on the behaviour of price levels. 
inflation into the expected and unexpected part. But how do people form expectations following a dramatic regime change? While there was, at times, significant inflation in Poland prior to the "big bang" transition, its nature was quite different than the subsequent inflationary process. ${ }^{13}$ Most prices (with the exception of fruits, vegetables as well as prices in street markets) were regulated and price increases required approval of the planning authorities. In all stores (with the exception of street markets) prices were identical. Inflation in 1980's was a result of the planners' attempt to reduce rampant shortages. The rate of inflation was determined by the whim of bureaucrats, rather than by observable things like the money supply; even the degree of shortages for individual goods did not play much role. Moreover, the big-bang reforms in January 1990 changed completely the organization of the economy (for example the exchange rate policy), altering the relationship between inflation and aggregate variables. Hence any expectation mechanism or "rules-of-thumb" developed prior to 1990 were useless for the period following the jump to a market economy. Finally, an additional difficulty for the Lucas' approach is that the past history of local real shocks is an unreliable predictor of the current shock structure.

The data therefore provide us with a natural experiment in expectation formation. One of the goals of the paper is to infer from our results how expectations are formed, and what they depend on. Of course, the evidence is only tentative as the regression results we obtain can be at best viewed as applying to the joint hypotheses about the price changing regime and expectation formation.

A crucial distinction for empirical results is that between expected and unexpected

${ }^{13}$ Until 1970 the inflation rate was low, in the range of 0-3\% per year. In 1970's it varied between 0 and 10\%. In 1981-88 there was unprecedented (in a planned economy) inflation, which varied between 11\% (1985) and 103\% (1982). In the fall of 1989 most prices were freed and inflation reached over $200 \%$ in that year. 
inflation. Ideally, we would like to have a measure of expected aggregate inflation as well as measures of expected own (individual product) inflation rates. There are several estimates for the expected CPI rate of inflation in Poland. They are produced by various research institutes; Reuters collect survey data. Unfortunately, they do not cover the whole period of study. Even if they did, there were large relative price changes resulting from the adjustment of artificial pattern of relative prices, created by the planner and by rampant shortages, to a pattern dictated by the market. In these conditions the expected CPI inflation may have little effect on the behaviour of prices for a particular good. We construct expected CPI inflation by regressing inflation on its past values, time, time squared and monthly dummies. The measure of expected own inflation is obtained in a similar fashion, except that we include past values of own inflation and of CPI inflation. To make things as simple as possible, we chose a model with three lags of the dependent variable (and three lags of CPI in the regressions for own inflation). Time and time squared are included to control for transitioninduced changes in the economy structure; monthly dummies control for seasonal effects. We take the explained part of inflation to be the expected inflation and the residual to be the unexpected one.

We choose this simple approach for two reasons. First, given the degree of disaggregation in our data, collecting additional market-level information was not practical. Second, we want to compare the results to those obtained by Lach and Tsiddon (1992). There is an advantage of using a simple approach in a comparison like this, as it avoids atheoretical "massaging" the data. In the end our approach is similar to that in Lach and Tsiddon (1992). ${ }^{14}$

14 They construct the measures of expected own inflation by regressing inflation on past values of own and of CPI inflation and various time-related dummies. The lags are chosen on the basis of F-test. In the end, they select three lags of the CPI for all goods, and three lags of the dependent variable for $80 \%$ of goods. In our case CPI inflation has little 


\section{V.4. Estimation Procedure.}

We ran OLS regressions with various measures of own inflation and aggregate inflation, as well as time, time squared and monthly dummies as explanatory variables. The dependent variables are the two measures of variability (equations (1) and (2)). Own inflation serves as a proxy for changes in demand/supply conditions in a given market (which affect the price bounds in the menu cost model -Cecchetti, 1986) and for local conditions in the aggregate/local confusion approach. The data used for own inflation are national averages for the given good, rather than in-sample averages. In order to calculate the rate of inflation for a particular good GUS first calculates the price level in each voivodship and then computes the national price level as the unweighted average of the 49 voivodship values. Our data cover 4 out of the 49 voivodships, or about $8 \%$ of GUS's sample. Time is included as a proxy for structural change; we expect the change to be fast initially and slow down over time, as the economy approaches the new equilibrium. To account for this we include time squared. Finally, monthly dummies are included as we have many seasonal goods.

As the inflation rate, as well as both measures of relative price variability, were very high at the beginning of 1990, we estimated the relationships using data for the period 5/1990-12/1996. The exclusion of the February-April 1990 data (we cannot calculate price changes for January 1990) allows to avoid the results being dominated by the three outliers. If these months are included, the positive relationship between inflation and relative price variability is much stronger. Eliminating the subsequent months has little effect on the results. The additional benefit is that all regressions cover the same period (the measure of expected inflation can be calculated from April 1990 on).

effect, due to large changes in relative prices. 
We found that the stochastic components have nonspherical distribution. One reason may be that our sample is unbalanced: not every good is quoted in every location every time. So, for some locations, we were not able to calculate the monthly inflation rates and hence the number of observations over which we calculate SDP varies over time and over goods.

Durbin-Watson statistics indicated significant autocorrelations. This was confirmed when we tried to estimate the model with the Maximum Likelihood method using different $\mathrm{AR}(\mathrm{p})$ specifications for the disturbances: the lagged values of disturbances turned out to be statistically significant.

We tried to find a way to estimate the models more efficiently than by OLS. Experiments with $\operatorname{AR}(\mathrm{p})$ specifications showed that the distribution of the disturbances is not simple. For example, when we tried an AR(12) model, different lags turned out to be significant for different goods, without any visible pattern. Besides, in several cases the ML estimation could not be conducted because, at the initial estimates, the distribution was nonstationary under the hypothesis of $\mathrm{AR}(12)$.

These observations led us to use simple OLS estimation with consistent non-parametric estimation of standard errors. Despite the loss of efficiency, this approach is used because, first, the results are still significant and, second, the complex form of the distribution of disturbances could cause loss of consistency if the AR(p) model is misspecified. Newey and West (1994) and Andrews and Monahan (1992) describe the nonparametric kernel method. We use a quadratic-spectral kernel as described in Andrews (1991) and Andrews and Monahan (1992); this kernel is recommended based on Monte Carlo simulations. We also use a prewhitening procedure suggested in Andrews and Monahan (1992) and automatic lag selection described in Newey and West (1992).

We also tried to estimate the model as a seemingly unrelated regression system. The 
coefficients were quite similar and they were significant in similar instances as those in OLS estimation. As we don't know the true form of the covariance matrix of the disturbances, however, we cannot be sure that these estimates are more efficient than the OLS ones. Also, in our model, (rational) expectations play a crucial role and we don't know how exactly these are formed on the basis of observed variables and available information. Under those circumstances SUR estimators may be inconsistent. We decided not to draw any conclusions from these estimates and they are not reported here.

\section{V.5. Results.}

Regression results are in tables 5-7. Table 5 summarizes, for the SDP measure of variability, the following regression:

$$
S D P_{i t}=\alpha_{\mathrm{io}}+\alpha_{\mathrm{i} 1} \Pi_{\mathrm{it}}+\alpha_{\mathrm{i} 2} t+\alpha_{\mathrm{i} 3} t^{2}+\boldsymbol{\alpha d} d_{m d}+u_{\mathrm{it}}
$$

where $\Pi_{\mathrm{it}}$ is own inflation of good $i$ at time $t$ and $\boldsymbol{d}_{\boldsymbol{m}}$ is the vector of monthly dummies. In columns 3-4 the specification is:

$$
S D P_{i t}=\beta_{\mathrm{io}}+\beta_{\mathrm{i} 1} E \Pi_{\mathrm{it}}+\beta_{\mathrm{i} 2} U \Pi_{\mathrm{it}}+\beta_{\mathrm{i} 3} t+\beta_{\mathrm{i} 4} t^{2}+\boldsymbol{\beta} \boldsymbol{d}_{m \boldsymbol{d}}+e_{\mathrm{it}}
$$

where $E \Pi_{\mathrm{it}}$ and $U \Pi_{\mathrm{it}}$ are the expected and unexpected parts of own inflation, obtained as described in section V.3. above. These are, essentially, the same regression as in Lach and Tsiddon (their equations (2') and (2), respectively); the differences are that we include time and time squared as well as monthly dummies. The motivation for including the additional variables is discussed in section V.4. above.

Column 1 of Table 5 shows that relative price variability, as measured by standard deviation of the rates of price change, is positively related to the inflation rate. The coefficient on inflation is positive for most goods; it is positive and significant for 38 out of the 52 goods (in all cases significance is at the 5\% level). The coefficient is never negative and significant. When inflation is separated into its expected and unexpected components 
(columns 3 and 4) it is clear that the effect of expected inflation is stronger than the effect of unexpected inflation: the average coefficient on expected inflation is twice bigger and it is significant for more goods. It is negative and significant for one good (citric acid). The effect of time is as predicted: variability falls with time but at a decreasing rate. The average coefficient on time (i.e. the marginal effect of time equal to $\hat{\alpha}_{i 2}+2 \hat{\alpha}_{i 3} t$ evaluated at sample mean, where $\hat{\alpha}$ is the estimated coefficient in equation (3); and similarly for equation 4) is negative for all 52 goods in regression (3) and for 50 goods in regression (4). Monthly dummies are jointly significant, hence the results confirm the additional variables should be included in the regressions.

Alternative specifications are in columns 2 and 5-6. In column 2 we summarize the results obtained by replacing own inflation in equation (3) with its absolute value. The results are a bit stronger: the average effect on variability increases by over $10 \%$ and it is significant for additional two goods. The most clear-cut are the results in columns 5-6, where the expected and unexpected components of inflation have been replaced in equation (4) by their absolute values. The average coefficient on the absolute value of expected inflation is an order of magnitude bigger than the average coefficient on the absolute value of unexpected inflation.

Results for individual goods are in table 6 . The coefficient on expected inflation is larger than on unexpected inflation for 40 out of 52 goods; the difference is significant for 13 goods (the corresponding numbers in Lach and Tsiddon (1992) are 16 and 5 out of 26).

The results are, qualitatively, identical to the benchmark results in Lach and Tsiddon (1992). This is despite the fact that the method of calculating expected inflation we use is, if anything, overly simplified. So the bottom line is this: it takes sellers of sausage, eggs, toothpaste, vacuum cleaners, car-wash operators etc. just a few years to figure out how to 
adjust prices in a market environment. Together with the results in the companion paper (Konieczny and Skrzypacz, 1999), this indicates that agents learn fast.

Quantitatively, some results are very similar: the average coefficient on expected inflation in regression (3) is 0.43 in the Polish data and 0.41 in the Israeli data; the average coefficient on unexpected inflation in regression (4) is 0.32 and 0.36 , respectively. On the other hand, the average coefficient on expected inflation is much larger in the Polish data (0.66; it is 0.43 in Lach and Tsiddon). Hence in the Polish data the average coefficient on expected inflation is twice larger than the average coefficient on unexpected inflation, while in the Israeli data the difference is only $20 \%$.

What is responsible for the stronger effect of expected inflation on relative price variability in the Polish data? We can only speculate that, despite the fluid economic environment, the inflation rate was easier to predict. The inflation rate is lower than in Israel: except for the first four months in 1990 (which are excluded from the regressions) the monthly rate exceeds $3.9 \%$ (the average inflation rate in Israel in 1978-79 - the low inflation period in Lach and Tsiddon's study) in 18 out of 84 months; it exceeds $7.3 \%$ (the average inflation rate in Israel in 1982 - the high inflation period) in only 2 out of 84 months. While it is impossible to know how predictable the inflation rate was, given the large-scale macroeconomic changes, there are several reasons to believe that in later years the inflation rate was relatively easy to forecast. The inflation rate falls systematically over time. While the monthly inflation rate is erratic, the 12-month inflation rate falls, compared with the analogous period in the previous year, in 64 out of 72 months. From 1992 on, the standard deviation of the monthly inflation rate in the previous 12 months is quite stable, varying between 1 and $1.5 \%$. With the exception of 1994, the inflation rate is predictably high in January, largely due to increases in regulated prices. Note, however, that these arguments 
apply only to CPI inflation while evidence discussed above is based on own inflation rates.

The effect of CPI inflation, summarized in columns 7-9 of Table 5, present a similar picture to those obtained using own inflation, but their explanatory power is lower: while some coefficients are larger, so are standard errors and so the regressions are significant only for $1 / 4$ of the goods. In columns 10-11 we summarize the results of regression in which the explanatory variables are own inflation and CPI inflation. The effect of own inflation is much stronger than for CPI inflation; the latter is rarely significant. This is not surprising, as there were large relative price changes during transition from the artificial relative price structure imposed by planners to relative prices dictated by the market.

Finally, in Table 7 we summarize results of regressions in which the left hand side variable is the coefficient of variation of price levels. The results are similar to those obtained for the SDP measure of variability, but less significant. This is consistent with an environment in which menu costs matter but firms do not continually revise price bounds. In these circumstances an increase of inflation rate causes, essentially, a reordering of firms with respect to their real price (ie firms which have just changed price move from having the lowest to having the highest price) but there is little effect on the distribution of price levels. On the other hand, as more firms are changing prices, the SDP measure of price variability increases (as long as fewer than half firms change prices in each period, which is the case in our data).

\section{Are Price Setters Forward Looking?}

While the results in the previous section are consistent with the menu cost explanation of price adjustment, the modelling of expectations is unsatisfactory. The menu cost model assumes that agents are forward-looking: the optimal price bounds are set on the basis of the 
expected future inflation. The measure of inflation used in section $\mathrm{V}$, however, is simply a weighted average of the inflation rates in the previous three months. Hence it is not clear whether price setters' expectations are, indeed, forward-looking.

One way of discovering the nature of expectations is to regress variability on inflation rates in various months. The problem with this approach is that inflation rates in adjacent months are strongly correlated. Even if the true model is that it is the current inflation that matters, the estimated coefficients on inflation rates in the previous month, for example, would often be significant. In the absence of a structural model, it is difficult to find out which inflation rate matters by looking at results of these regressions. Hence we do not present those results.

We are able to infer the nature of expectations using the high frequency (three times a month) data, which are available for the period 1991-96 for 40 foodstuffs. We regress the SDP measure of relative price variability, separately for each 10-day period, on last month's, current and next month's inflation. The intuition is as follows. Assume that price changes are based on expectations of inflation and that expectations are correlated with actual inflation. If expectations are forward looking, as time progresses and new information is acquired, the effect of last month's inflation should decline, and the effect of current month's inflation should increase. Hence we run the following regression:

$$
\operatorname{SDP}_{i t}^{k}=\gamma_{i o}+\gamma_{i 1} \Pi_{i(t-1)}+\gamma_{i 2} \Pi_{i t}+\gamma_{i 3} \Pi_{i(t+1)}+\gamma_{i 4} t+\gamma_{i 5} t^{2}+\gamma d_{M D}+v_{i t}
$$

The results are in Table 8. As time progresses the explanatory power of next month's inflation increases, at the expense of explanatory power of both the current and previous month's inflation. The average coefficient on $\Pi_{i(t+1)}$ is a half of the coefficient on $\Pi_{i(t-1)}$ in the regressions in which the dependent variable is computed using data from the first ten days of each month; when the data are from the last 10 days of the month it is four times larger. In 
the latter case the coefficient is positive and significant for almost $40 \%$ of the goods in the sample; it is never negative and significant. In contrast, the explanatory power of past month's inflation falls as time progresses; in regressions in which the dependent variable is computed using data from the last 10 days in each month the average coefficient is negative. Overall, the results suggest that price setters have forward-looking expectations.

\section{Conclusions.}

In this paper we analyze the relationship between inflation and relative price variability using a disaggregated data set for Poland. The period covered starts at the beginning of the big-bang transformation of the Polish economy. Even though the economy is undergoing transition unlike anything encountered in earlier studies of the relationship, the results are remarkably similar to those obtained for low and high inflation market economies. Inflation increases relative price variability and it is the expected, rather than unexpected, inflation rate that matters. As the inflation rate falls, the duration of price quotations increases and price changes become smaller.

While we do not test the menu cost model directly, data appear to be broadly consistent with its predictions. Regression results, as in Lach and Tsiddon (1992) support menu costs as an explanation of price variability over the aggregate/local confusion of the Lucas' (1973) type.

Most importantly, in our view, the results indicate an astonishing degree of rationality among price setters. Together with the evidence in the companion paper (Konieczny and Skrzypacz, 1999) the results suggest that learning curve is really steep. The results indicate that price-setters form forward looking expectations and that they form expectations rationally or near-rationally. 
The results have clear implications for policy making in transition economies.

Despite the lack of experience with market-driven good allocations, at the individual level agents behave precisely as theory, and evidence from advanced market economies, suggest. This means that policymakers should not be afraid that households will not respond correctly to market incentives and should concentrate on reforming institutions. 


\section{REFERENCES.}

Andrews, Donald W.K. (1991), Improved Heteroskedasticity and Autocorellation Consistent Covariance Matrix Estimation, Econometrica, 817-858.

Andrews, Donald W.K. and J. Christopher Monahan (1992), An Improved Heteroskedasticity and Autocorellation Consistent Covariance Matrix Estimator, Econometrica, 953-966.

Barro, Robert (1972), A Theory of Monopolistic Price Adjustment, Review of Economic Studies, 17-26.

Barro, Robert. J. (1976), Rational Expectations and the Role of Monetary Policy, Journal of Monetary Economics, 1-32.

Bauc, Jarosław, Marek Belka, Andrzej Czyżewski and Andrzej Wojtyna (1996), Inflacja w Polsce 1990-95 (Inflation in Poland 1990-95), Warsaw.

Caplin Andrew S. and Daniel F. Spulber (1987), Menu Costs and the Neutrality of Money, Quarterly Journal of Economics, 703-26.

Caplin, Andrew and John Leahy (1991), State Dependent Pricing and the Dynamics of Money and Output, Quarterly Journal of Economics, 683-708.

Cecchetti, Stephen G. (1986), The Frequency of Price Adjustment: A Study of the Newsstand Prices of Magazines, Journal of Econometrics, 255-74.

Cukierman, Alex (1984), Inflation, Stagflation, Relative Prices and Imperfect Information, Cambridge.

Dahlby, Beverly (1992), Price Adjustment in an Automobile Insurance Market: A Test of the Sheshinski-Weiss Model, Canadian Journal of Economics, 564-83. 
Danziger, Leif (1987), Inflation, Fixed Costs of Price Adjustment and the Measurement of Relative-Price Variability: Theory and Evidence, American Economic Review, 70413.

Debelle, Guy and Owen Lamont (1997), Relative Price Variability and Inflation: Evidence from U.S. Cities, Journal of Political Economy, 132-152.

Domberger, Simon (1987), Relative Price Variability and Inflation: A Disaggregated Analysis, Journal of Political Economy, 547-66.

Fischer, Stanley (1977), Long-Term Contracts, Rational Expectations and the Optimal Money Supply Rule, Journal of Political Economy, 191-205.

Fisher, T. and J. D. Konieczny (1999a), Inflation And Price Adjustment: A Study Of Canadian Newspaper Prices, Wilfrid Laurier University, mimeo.

Fisher, T. and J. D. Konieczny (1999b), Synchronization of Price Changes by Multiproduct Firms: Evidence from Canadian Newspaper Prices, Wilfrid Laurier University, mimeo.

Kashyap, Anil K. (1995), Sticky Prices: New Evidence from Retail Catalogs, Quarterly Journal of Economics, 245-274.

Konieczny, Jerzy D. and Andrzej Skrzypacz (1999), Learning, Search and Arbitrage: Evidence from a Natural Experiment, Wilfrid Laurier University, mimeo.

Lach, Saul and Daniel Tsiddon (1992), The Behaviour of Prices and Inflation: An Empirical Analysis of Disaggregated Price Data, Journal of Political Economy, 349-89.

Lach, Saul and Daniel Tsiddon (1996), Staggering and Synchronization in Price-Setting: Evidence from Multi product Firms, American Economic Review, 1175-1196.

Levy, Daniel, Mark Bergen, Shantung Dutra and Robert Vendable (1997), The Magnitude of Menu Costs: Direct Evidence from Large U.S. Supermarket Chains, Quarterly 
Journal of Economics, 791-826.

Lucas, R. E. Jr (1982), Some International Evidence on Output-Unemployment Tradeoff, in his Studies in the Business Cycle Theory, MIT Press.

Mills, Frederic (1927), The Behaviour of Prices, New York.

Newey, Whitney K. and Kenneth D. West (1994), Automatic Lag Selection in Covariance Matrix Estimation, Review of Economic Studies, 631-653.

Parks, Richard W. (1978), Inflation and Relative Price Variability, Journal of Political Economy, 79-95.

Parsley, David C. (1996), Inflation and Relative Price Variability in the Short and Long Run: New Evidence from the United States, Journal of Money, Credit and Banking, 32341.

Sachs Jeffrey D. (1993), Poland's Jump to the Market Economy, MIT Press.

Sheshinski, Eytan and Yoram Weiss (1977), Inflation and Costs of Price Adjustment, Review of Economic Studies, 287-303.

Sheshinski, Eytan and Yoram Weiss (1983), Optimum Pricing Policy and Stochastic Inflation, Review of Economic Studies, 513-29.

Sheshinski, Eytan, Tishler, A. and Yoram Weiss (1981), Inflation, Costs of Price Adjustment and Real Price Amplitude: An Empirical Study, in Development in an Inflationary World, M.J. Flanders and A. Razin, eds., Academic Press.

Taylor, John B. (1980), Aggregate Dynamics and Staggered Contracts, Journal of Political Economy, 1-23.

Tommasi, Mariano (1993), Inflation and Relative Prices: Evidence from Argentina, in Inflation and Cost of Price Adjustment, E. Sheshinski and Y. Weiss, eds. MIT Press. 
Van Hoomissen, Teresa (1988), Price Dispersion and Inflation: Evidence from Israel, Journal of Political Economy, 1303-14.

Vining, Daniel R. Jr. and Thomas C. Elwertowski (1976), The Relationship between Relative Prices and the General Price Level, American Economic Review, 699-708.

Weiss, Yoram (1993), Inflation and Price Adjustment: a Survey of Findings from MicroData, in Inflation and Cost of Price Adjustment, E. Sheshinski and Y. Weiss, eds. MIT Press. 


\section{Appendix A.}

\section{List of goods in monthly observations:}

1. Back bacon "Sopocka", 1kg; 2. Sausage "Krakowska sucha", 1 kg; 3. Sausage "Mysliwska sucha", 1 kg; 4. Sausage "Krakowska parzona", 1kg; 5. Sausage "Zwyczajna", 1kg; 6. Pork wieners, 1 kg; 7. Sausage "Torunska", 1 kg; 8. Sausage "Zywiecka", 1 kg; 9. Eggs, each; 10. Herring, salted, $1 \mathrm{~kg} ; 11$. Sprats, smoked, $1 \mathrm{~kg} ; 12$. Powdered baby milk, $500 \mathrm{~g} ; 13$. Cheese "Gouda", $1 \mathrm{~kg} ; 14$. Cheese "Edamski", $1 \mathrm{~kg} ; 15$. Butter, $82.5 \%$ fat, 250g; 16. Flour "Tortowa", 1 kg; 17. Flour "Krupczatka", 1 kg; 18. Flour "Poznanska", 1 kg; 19. Pearl barley "Mazurska", 1 kg; 20. Rye bread, 1 kg; 21. Bread "Baltonowski", 1 kg; 22. Bread "Wiejski", 1 kg; 23. Sugar, 1 kg; 24. Plum butter, 460g jar; 25. Jam, blackcurrant, 460g jar; 26. Apple juice, 11 box; 27. Pickled cucumbers, 900g jar; 28. Margarine "Palma", 250g; 29. Veggie butter, 250g tub; 30. Candy "Krowka", $1 \mathrm{~kg} ; 31$. Cookies "Delicje szampanskie", 1kg; 32. Cookies "Petit Beurre" type, 100g; 33. Pretzel sticks, 100g; 34. Halvah, $1 \mathrm{~kg}$; 35. Vinegar, 10\%, 0.51 bottle; 36. Citric acid, $10 \mathrm{~g}$ bag; 37. Tea "Madras", packed domestically, 100g; 38. Mineral water in a cafeteria, 0.331 bottle; 39. Pastry "W-Z" in a café, each; 40. Razor blade "Polsilver", each; 41. Vacuum cleaner, type 338,5; 42. Kitchen mixer, type 175,5; 43. Folding bicycle "Wigry-3"; 44. Radio receiver "Ania" 45. Paint thinner, 0.51; 46. Toothpaste "Pollena", 98g; 47. Shaving cream; 48. Sanitary pads "Donna", box of 20; 49. Car-wash, of car: "FSO 1500"; 50. Varnishing of hardwood floor, twice, $1 \mathrm{~m}^{2}$; 51. EKG test; 52. Radiator coolant "Borygo" or "Petrygo", 11.

\section{List of goods with observations three times a month:}

Goods 1-37, plus: 53. Salt, white, $1 \mathrm{~kg}$; 54. Luncheon Meat, $1 \mathrm{~kg} ; 55$. Condensed milk, unsweetened, $411 \mathrm{~g}$. 
Figure 1

General Characteristics of the Data

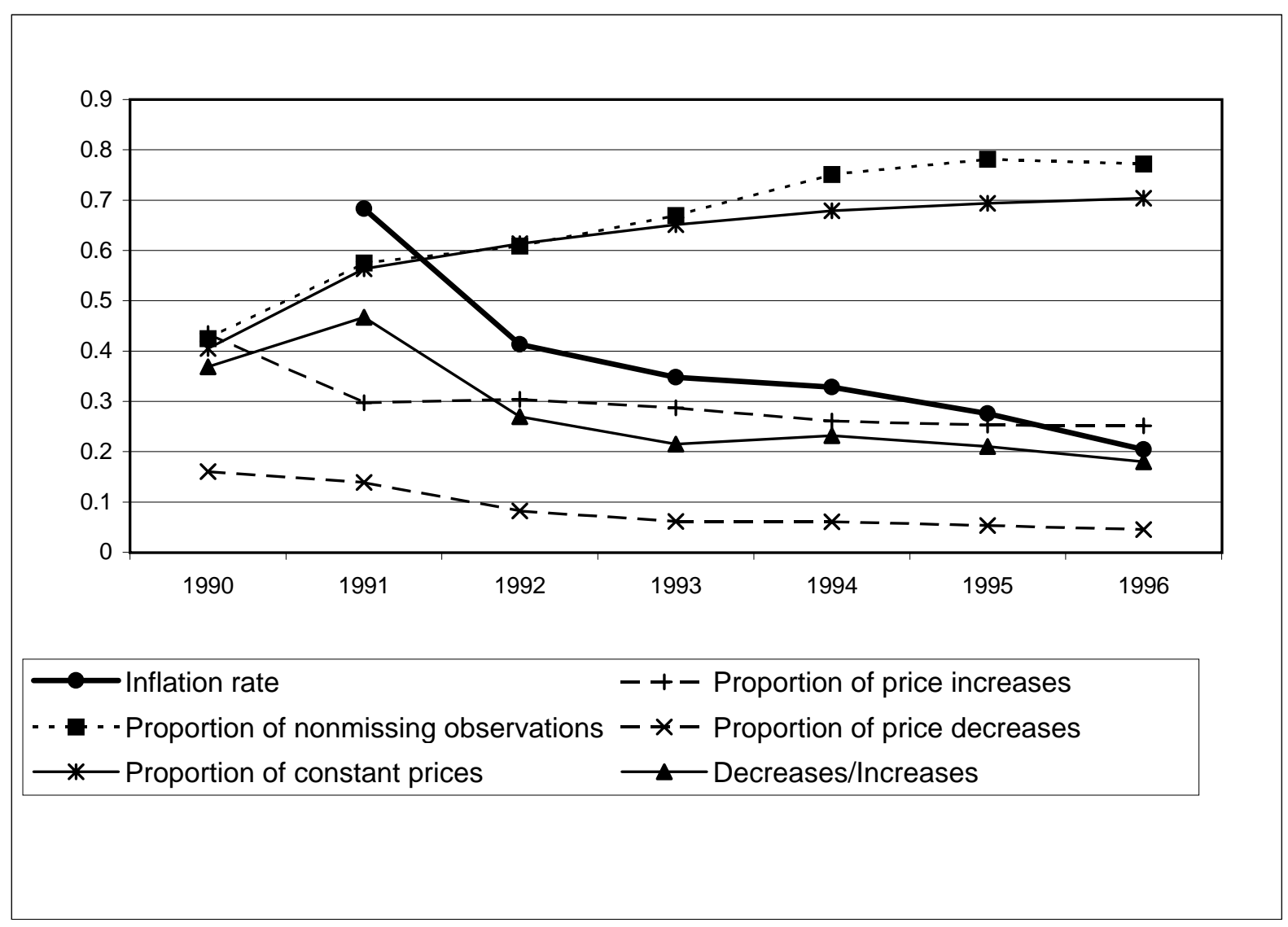


Table 1

Changes in Store Ownership

\begin{tabular}{|r|r|r|r|}
\hline Year & Total & State Owned & Cooperative \\
\hline 1990 & 237425 & 14312 & 68454 \\
1991 & 310966 & 9440 & 51044 \\
1992 & 352502 & 9613 & 42448 \\
1993 & 380582 & 8620 & 36187 \\
1994 & 415449 & 7533 & 32369 \\
1995 & 425600 & 6287 & 29372 \\
1996 & 405563 & 5399 & 26316 \\
\hline
\end{tabular}

Sources:

Rynek wewnetrzny w 1993 r. (Domestic Market in 1993), GUS, Warsaw, 1994 Notatka informacyjna dotyczaca publikacji "Rynek Wewnetrzny w 1996r."

(Information Note on the Publication "Domestic Market in 1996"),

GUS, Warsaw, July 1997 
Table 2

The Duration of Prices and the Size of Price Changes

\begin{tabular}{|r|l|l|l|l|}
\hline Year & $\begin{array}{l}\text { Inflation } \\
\text { rate } \\
\text { in \% per year }\end{array}$ & $\begin{array}{l}\text { lverage } \\
\text { duration of } \\
\text { prices } \\
\text { (months) }\end{array}$ & $\begin{array}{l}\text { lverage } \\
\text { price } \\
\text { increase } \\
\text { in \% }\end{array}$ & $\begin{array}{l}\text { Average } \\
\text { price } \\
\text { decrease } \\
\text { in \% }\end{array}$ \\
\hline $1990-96$ & 54.23 & 2.39 & 14.42 & -9.45 \\
\hline 1990 & 249.3 & 1.43 & 32.92 & -12.39 \\
1991 & 60.4 & 1.85 & 15.42 & -9.94 \\
1992 & 44.3 & 2.33 & 13.19 & -8.95 \\
1993 & 37.6 & 2.62 & 11.09 & -7.28 \\
1994 & 29.5 & 2.77 & 9.35 & -8.24 \\
1995 & 21.6 & 2.69 & 9.87 & -7.54 \\
1996 & 18.5 & 3.12 & 9.05 & -9.42 \\
\hline
\end{tabular}

Source: GUS 
Table 4

\section{Proportion of Price Changes} by 10-day Periods

\begin{tabular}{|c|c|c|c|}
\hline Year & Observation & \multicolumn{2}{|c|}{ Proportion of all } \\
& in each month & \multicolumn{2}{|c|}{$\begin{array}{c}\text { increases } \\
\text { during the month }\end{array}$} \\
\hline 1991 & 1 & 0.49 & 0.59 \\
& 2 & 0.29 & 0.20 \\
& 3 & 0.23 & 0.21 \\
\hline 1992 & 1 & 0.56 & 0.64 \\
& 2 & 0.24 & 0.18 \\
& 3 & 0.20 & 0.18 \\
\hline 1993 & 1 & 0.52 & 0.60 \\
& 2 & 0.24 & 0.20 \\
& 3 & 0.24 & 0.20 \\
\hline 1994 & 1 & 0.59 & 0.63 \\
& 2 & 0.20 & 0.18 \\
& 3 & 0.21 & 0.18 \\
\hline 1995 & 1 & 0.61 & 0.66 \\
& 2 & 0.21 & 0.18 \\
& 3 & 0.18 & 0.17 \\
\hline 1996 & 1 & 0.58 & 0.61 \\
& 2 & 0.23 & 0.20 \\
& 3 & 0.19 & 0.19 \\
\hline
\end{tabular}




\begin{tabular}{|c|c|c|c|c|c|c|c|c|}
\hline 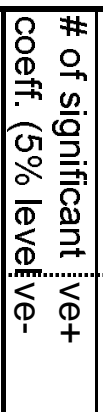 & | & 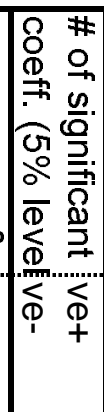 & | & 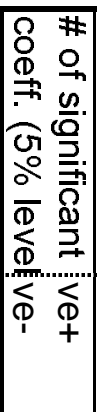 & 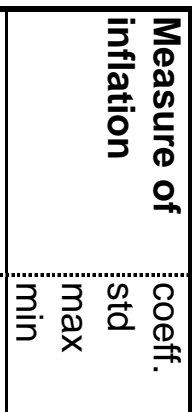 & 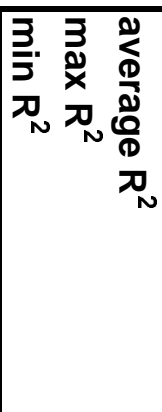 & 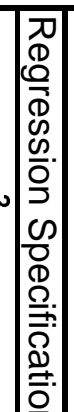 & $\frac{8}{\frac{2}{3}}$ \\
\hline 임 & 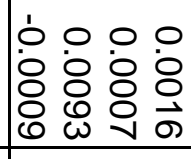 & $\ddot{\omega}_{0}$ & 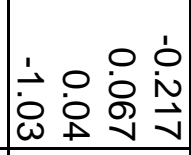 & $\begin{array}{ll} & \\
0 & \infty \\
\end{array}$ & 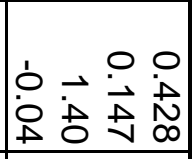 & $\begin{array}{lll}0 & 0 & 0 \\
\text { N } & 0 & 0 \\
\text { G } & 0 & 0\end{array}$ & $\begin{array}{l}\bar{z} \\
\overline{7} \\
\overline{+}\end{array}$ & 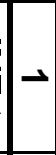 \\
\hline ○ ని & $\begin{array}{l}1 \\
1 \\
\circ \\
8\end{array}$ & $\underline{v}_{0}$ & 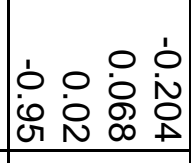 & 00 & 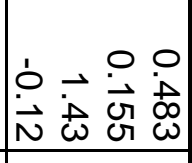 & $\begin{array}{lll}0 & 0 & 0 \\
\text { in } & 0 & 0 \\
\infty & 0 & 0 \\
\end{array}$ & $\begin{array}{l}\overline{\bar{\Sigma}} \\
\overline{\mathbf{T}} \\
\bar{E}\end{array}$ & N \\
\hline$\sim \widetilde{\sigma}$ & 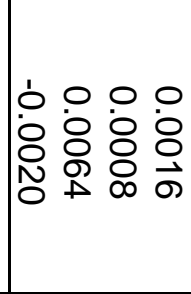 & $\omega$ & 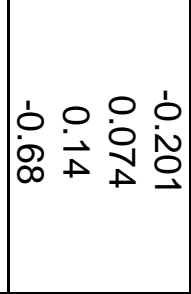 & 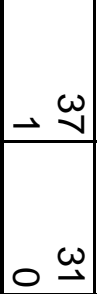 & 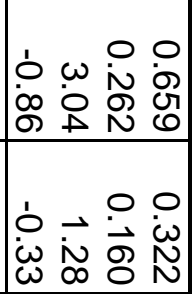 & 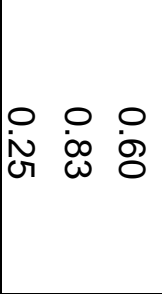 & 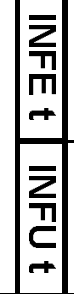 & $\omega$ \\
\hline$-N$ & 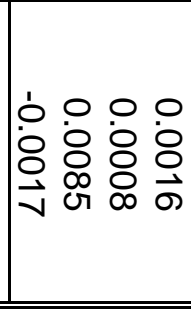 & $\omega$ & 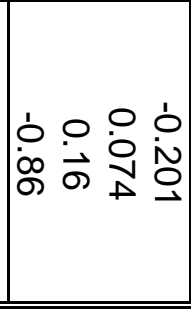 & 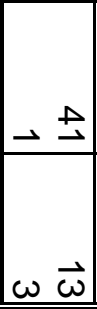 & 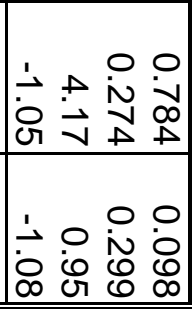 & 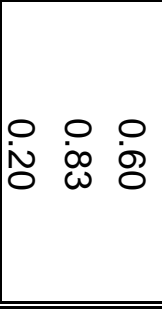 & 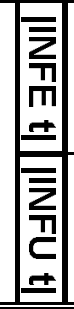 & or \\
\hline ○ N & 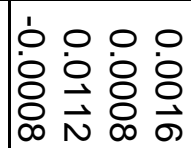 & $\omega_{\omega} 0$ & 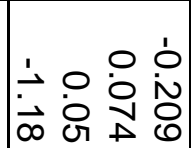 & $-\vec{N}$ & 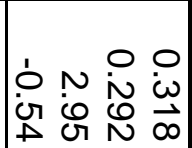 & 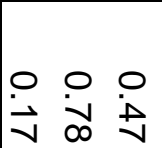 & $\frac{\rho}{\mathrm{g}}$ & $v$ \\
\hline$\circ \vec{\omega}$ & 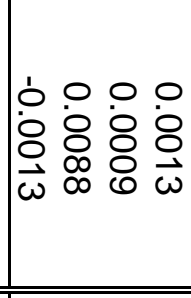 & बे & 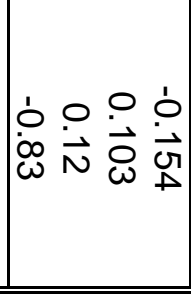 & $\begin{array}{l}\circ \vec{G} \\
-\vec{ت}\end{array}$ & 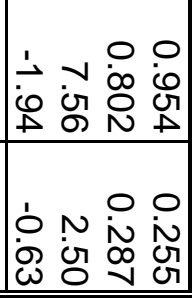 & $\begin{array}{lll}\circ & \circ & \circ \\
\dot{\infty} & \infty & 0 \\
& \infty & 0\end{array}$ & 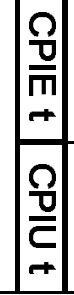 & $\mid \infty$ \\
\hline 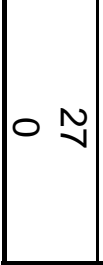 & 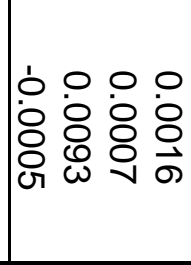 & $\underline{v}_{0} 0$ & 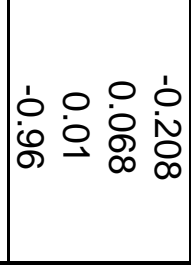 & $\begin{array}{ll}0 & \omega \\
& \\
\omega & \sigma\end{array}$ & 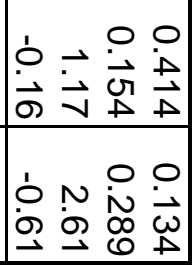 & 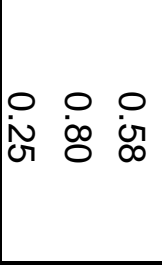 & \begin{tabular}{|l|}
$\bar{z}$ \\
+ \\
$\rho$ \\
$\underline{0}$ \\
+
\end{tabular} & $\overrightarrow{0}$ \\
\hline
\end{tabular}

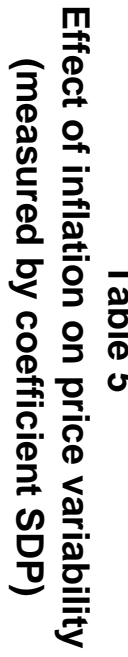


Table 6

Effect of inflation on price variability

(measured by coefficient SDP)

Results for individual goods

\begin{tabular}{|c|c|c|c|c|c|}
\hline Column & 1 & 3 & 4 & 5 & 6 \\
\hline $\begin{array}{l}\text { Regression } \\
\text { Specification }\end{array}$ & INF $\mathrm{t}$ & INFE $\mathbf{t}$ & INFU t & |INFE t| & |INFU t| \\
\hline Good & \multicolumn{5}{|c|}{ coefficients ("*" denotes significance at $10 \%$ level and "**" at $5 \%$ ) } \\
\hline 1 & $0.26^{\star \star *}$ & $0.45^{\star *}$ & $0.23^{\star *}$ & $0.60^{\star \star}$ & $0.23^{\star \star}$ \\
\hline 2 & $0.21 * \star$ & $0.65 * *$ & 0.08 & $1.00 * *$ & 0.23 \\
\hline 3 & 0.05 & $1.07 * *$ & -0.17 & $1.26 * *$ & -0.03 \\
\hline 4 & $0.30 * *$ & $0.67 * \star$ & $0.18 * \star$ & $0.89 * *$ & 0.07 \\
\hline 5 & $0.26 * *$ & $0.54 * *$ & $0.18^{* *}$ & $0.77^{* *}$ & -0.11 \\
\hline 6 & $0.21 * *$ & $0.98 * *$ & -0.02 & $1.23 * *$ & -0.11 \\
\hline 7 & $0.19 * *$ & $0.51 * \star$ & 0.09 & $1.00 * *$ & 0.18 * \\
\hline 8 & $0.30 * *$ & $0.60 * *$ & $0.22^{* *}$ & $0.68 * *$ & 0.22 * \\
\hline 9 & -0.04 & -0.07 & -0.04 & $0.26 * *$ & 0.05 \\
\hline 10 & 0.14 & $0.33 * *$ & -0.03 & $0.41 * *$ & $-0.79 * \star$ \\
\hline 11 & 0.09 & -0.14 & 0.23 ** & -0.17 & -0.22 \\
\hline 12 & $0.50 * *$ & 0.64 ** & 0.39 ** & $0.53 * *$ & $0.40 * *$ \\
\hline 13 & $0.42 * *$ & $0.44^{* *}$ & $0.37^{* *}$ & $0.47 * *$ & 0.13 \\
\hline 14 & $0.41 * *$ & $0.41 * *$ & $0.39^{* *}$ & $0.36 * *$ & 0.46 \\
\hline 15 & $0.11 * \star$ & $0.15 * \star$ & 0.07 & $0.15 * \star$ & 0.25 ** \\
\hline 16 & $0.52 * *$ & $0.74^{* *}$ & 0.34 ** & $0.72 * *$ & 0.42 ** \\
\hline 17 & $0.59 * *$ & $0.75^{* *}$ & $0.38^{* *}$ & $0.68 * *$ & $0.59^{* *}$ \\
\hline 18 & $0.36 * *$ & $0.66 * *$ & 0.20 ** & $0.66 * *$ & 0.24 ** \\
\hline 19 & $0.65 * *$ & $0.78^{* \star}$ & 0.37 ** & $0.87^{* *}$ & 0.19 \\
\hline 20 & $0.70 * *$ & $1.12 * *$ & 0.53 ** & $0.99 * *$ & 0.33 \\
\hline 21 & $0.35 * *$ & $0.49 * *$ & $0.27^{* *}$ & $0.44^{* *}$ & 0.26 ** \\
\hline 22 & $0.36 * \star$ & $0.51 * \star$ & 0.27 ** & $0.47^{* \star}$ & 0.12 \\
\hline 23 & $0.12 * *$ & -0.41 & $0.13^{* *}$ & 0.29 & $0.26^{* *}$ \\
\hline 24 & $1.06 * *$ & $1.49 * *$ & 0.69 ** & $1.53 * *$ & $0.95 * *$ \\
\hline 25 & $1.40 * *$ & $1.54 * *$ & $1.28^{* *}$ & $1.62 * *$ & -0.33 \\
\hline 26 & 0.27 & -0.21 & $1.08^{* *}$ & -0.23 & 0.03 \\
\hline 27 & $0.31 * *$ & $0.36 * *$ & 0.12 & $0.37^{\star *}$ & 0.29 \\
\hline 28 & $0.57 * *$ & $0.74^{* *}$ & $0.45^{* *}$ & $0.70 * *$ & 0.39 \\
\hline 29 & $0.51 * \star$ & $0.38 * \star$ & 0.59 ** & $0.43^{* *}$ & $0.77^{* *}$ \\
\hline 30 & $0.67 * *$ & $0.92 * *$ & $0.45^{* *}$ & $0.95 * *$ & -0.42 \\
\hline 31 & $0.41 * *$ & $1.83 * *$ & $0.27^{* *}$ & $1.88 * *$ & 0.10 \\
\hline 32 & 0.30 & $0.97 *$ & 0.15 & $1.12 * *$ & 0.07 \\
\hline 33 & $0.75 * *$ & 0.37 & $0.85^{* *}$ & 0.35 & $0.86^{* *}$ \\
\hline
\end{tabular}


Table 6

continued

\begin{tabular}{|c|c|c|c|c|c|}
\hline Column & 1 & 3 & 4 & 5 & 6 \\
\hline $\begin{array}{l}\text { Regression } \\
\text { Specification }\end{array}$ & INF $\mathbf{t}$ & INFE $\mathrm{t}$ & INFU t & |INFE t| & |INFU t| \\
\hline Good & \multicolumn{5}{|c|}{ coefficients ("*" denotes significance at $10 \%$ level and "**" at $5 \%$ ) } \\
\hline 34 & 0.05 & 0.05 & 0.04 & 0.06 & 0.30 \\
\hline 35 & $0.50 * *$ & $0.81 * *$ & 0.26 * & $1.05 * *$ & $-0.62 * *$ \\
\hline 36 & -0.04 & $-0.86 * *$ & 0.09 & 0.24 & -0.17 \\
\hline 37 & $0.58 * *$ & 0.92 ** & 0.09 & 0.98 ** & -0.30 \\
\hline 38 & $0.59 * *$ & 0.88 * & 0.54 & $0.94 * *$ & -0.67 \\
\hline 39 & -0.02 & -0.32 & 0.02 & -0.11 & -0.27 \\
\hline 40 & 0.86 ** & $2.89 * *$ & 0.56 * & $4.18^{* *}$ & -0.61 \\
\hline 41 & $0.51^{* *}$ & $0.60^{* *}$ & $0.42^{* *}$ & 0.94 ** & 0.41 * \\
\hline 42 & 0.57 ** & $0.93 * *$ & 0.38 ** & 0.98 ** & 0.64 ** \\
\hline 43 & 0.60 ** & 0.61 ** & 0.59 ** & $0.63^{* *}$ & 0.37 \\
\hline 44 & $0.68^{* *}$ & 0.94 ** & 0.54 ** & 0.83 ** & 0.76 ** \\
\hline 45 & $0.61^{* *}$ & 2.09 ** & 0.06 & 2.06 ** & -0.39 \\
\hline 46 & 0.68 * & $1.71^{* *}$ & -0.33 & 1.81 ** & 0.18 \\
\hline 47 & 0.87 ** & $3.04^{* *}$ & 0.55 & 2.85 ** & -1.08 ** \\
\hline 48 & 0.78 * & 0.70 & $0.88^{* *}$ & 1.50 ** & -0.07 \\
\hline 49 & 0.11 & -0.60 & 0.21 & -0.54 & 0.08 \\
\hline 50 & 0.02 & -0.50 & 0.17 & $-1.05 * \star$ & -0.04 \\
\hline 51 & 0.42 * & -0.69 & $0.55^{* *}$ & -0.60 & 0.32 \\
\hline 52 & $0.57 * *$ & 0.79 * & $0.53 * *$ & 0.77 & 0.21 \\
\hline
\end{tabular}




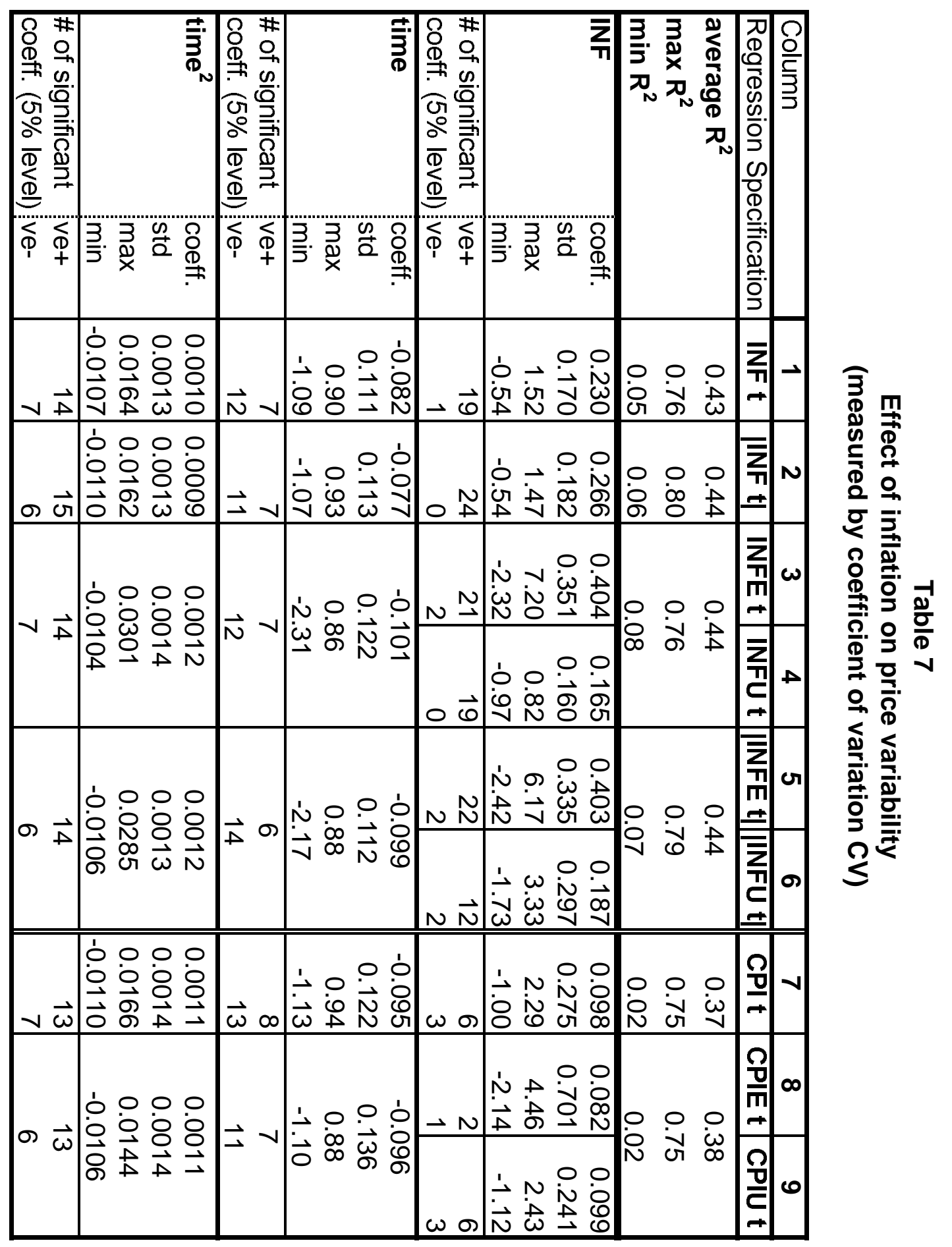


Table 8

Effect of inflation on price variability (measured by SDP) 10-DAY DATA

\begin{tabular}{|c|c|c|c|c|c|c|c|c|c|c|}
\hline \multicolumn{2}{|l|}{ Column } & 1 & 2 & 3 & 4 & 5 & 6 & 7 & 8 & 9 \\
\hline & & \multicolumn{3}{|c|}{ First 10 days } & \multicolumn{3}{|c|}{ Second ten days } & \multicolumn{3}{|c|}{ Third ten days } \\
\hline \multicolumn{2}{|c|}{ Regression Specification } & INF t-1 & INF t & INF $\mathbf{t + 1}$ & INF t-1 & INF t & INF $t+1$ & INF t-1 & INF t & INF $t+1$ \\
\hline \multirow{3}{*}{\multicolumn{2}{|c|}{$\begin{array}{l}\text { average } R^{2} \\
\max R^{2} \\
\min R^{2} \\
\end{array}$}} & \multicolumn{3}{|c|}{0.58} & \multicolumn{3}{|c|}{0.49} & \multicolumn{3}{|c|}{0.48} \\
\hline & & \multicolumn{3}{|c|}{0.89} & \multicolumn{3}{|c|}{0.87} & \multicolumn{3}{|c|}{0.91} \\
\hline & & \multicolumn{3}{|c|}{0.32} & \multicolumn{3}{|c|}{0.20} & \multicolumn{3}{|c|}{0.12} \\
\hline \multirow{4}{*}{ INF } & coeff. & 0.026 & 0.379 & 0.013 & 0.013 & 0.229 & 0.058 & -0.038 & 0.228 & 0.097 \\
\hline & std & 0.108 & 0.132 & 0.120 & 0.089 & 0.108 & 0.100 & 0.088 & 0.114 & 0.104 \\
\hline & $\max$ & 0.33 & 1.13 & 0.44 & 0.37 & 0.54 & 0.58 & 0.23 & 0.78 & 0.61 \\
\hline & $\min$ & -0.54 & -0.28 & -0.52 & -0.33 & -0.53 & -0.28 & -0.30 & -0.16 & -0.36 \\
\hline \multirow{2}{*}{$\begin{array}{l}\# \text { of significant } \\
\text { coeff. (5\% level) }\end{array}$} & ve+ & 7 & 31 & 3 & 5 & 28 & 4 & 2 & 21 & 15 \\
\hline & ve- & 4 & 0 & 4 & 4 & 0 & 1 & 6 & 0 & 0 \\
\hline \multirow{4}{*}{ time } & coeff. & \multicolumn{3}{|c|}{-0.105} & \multicolumn{3}{|c|}{-0.047} & \multicolumn{3}{|c|}{-0.038} \\
\hline & std & \multicolumn{2}{|r|}{0.047} & & \multicolumn{3}{|c|}{0.032} & \multicolumn{3}{|c|}{0.035} \\
\hline & $\max$ & \multicolumn{3}{|c|}{0.09} & \multicolumn{3}{|c|}{0.07} & \multicolumn{3}{|c|}{0.05} \\
\hline & $\min$ & \multicolumn{3}{|c|}{-0.32} & \multicolumn{3}{|c|}{-0.15} & \multicolumn{3}{|c|}{-0.15} \\
\hline \multirow{2}{*}{$\begin{array}{l}\text { \# of significant } \\
\text { coeff. ( } 5 \% \text { level) }\end{array}$} & & \multirow{2}{*}{\multicolumn{3}{|c|}{$\begin{array}{r}0 \\
25 \\
\end{array}$}} & & 1 & & & 0 & \\
\hline & ve- & & & & & 16 & & & 10 & \\
\hline time $^{2}$ & coeff. & & 0.0009 & & & 0.0004 & & & 0.0003 & \\
\hline & std & & 0.0006 & & & 0.0004 & & & 0.0004 & \\
\hline & $\max$ & & 0.0031 & & & 0.0015 & & & 0.0016 & \\
\hline & $\min$ & & \#\#\#\#\# & & & \#\#\#\#\# & & & \#\#\#\#\# & \\
\hline \# of significant & ve+ & & 18 & & & 12 & & & 6 & \\
\hline coeff. ( $5 \%$ level) & ve- & & 0 & & & 1 & & & 1 & \\
\hline
\end{tabular}

